\title{
Vein of Galen Aneurysmal Malformation: An Updated Review
}

\author{
Li-Rong $\mathrm{Cao}^{1}$ Chun-Quan Cai ${ }^{2}$ \\ ${ }^{1}$ Graduate College of Tianjin Medical University, Tianjin, China \\ ${ }^{2}$ Department of Neurosurgery, Tianjin Children's Hospital, Tianjin, China \\ J Pediatr Neurol 2019;17:45-56.
}

\begin{abstract}
Address for correspondence Chun-Quan Cai, PhD, Department of Neurosurgery, Tianjin Children's Hospital, Beichen District 300134, Tianjin, China (e-mail: cqcns6@126.com).
\end{abstract}

\begin{abstract}
Vein of Galen aneurysmal malformation (VGAM) is a rare intracranial vascular anomaly in the choroidal arteries characterized by the persistence of the embryonic median prosencephalic vein of Markowski (MProsV). It is common in children with high mortality and disability rates. VGAM-associated clinical presentations include heart failure, hydrocephalus, and neurological symptoms, which make it difficult for diagnosis. Simultaneously, the complex VGAM vascular architecture, characterized

Keywords

- vein of Galen aneurysmal malformation

- vein of Galen

- review by a wide interindividual variability, makes the management of this condition challenging to clinicians. Thus, timely diagnosis and treatment of VGAM are crucial. In this review article, we elucidated the latest research progresses of VGAM in the aspects of the pathogenesis, classification, clinical features, imaging, management, and prognosis based on recent relevant literatures. It is beneficial to raise the awareness of VGAM and improve the level of management and treatment.
\end{abstract}

\section{Introduction}

Vein of Galen aneurysmal malformation (VGAM) is a rare congenital intracranial arteriovenous deformation resulting from an anomalous fistulous connection between the primitive choroidal vessels and the most proximal part of the median prosencephalic vein of Markowski (MProsV). The incidence has been reported as 1:25,000. ${ }^{1}$ It accounts for $1 \%$ of cerebral vascular malformations and $30 \%$ of pediatric vascular malformations. ${ }^{2}$ Clinically, VGAM is commonly diagnosed during the neonatal period and early childhood according to the symptoms of congestive heart failure and intracranial hypertension.

Steinheil first described this abnormal intracranial arteriovenous connection as "varix aneurysm" in $1895 .{ }^{3}$ Since then, there were various terms used to depict this condition, including "vein of Galen malformation," "vein of Galen aneurysmal formation," "arteriovenous aneurysms of the vein of Galen," and "aneurysms of the vein of Galen." However, these medical terms are misnomers because the malformation is actually caused by MProsV, rather than the vein of Galen. The true VGAM was reported by Boldrey and Miller in 1949. ${ }^{4}$ The term

received

October 16, 2017

accepted after revision

January 23, 2018

published online

April 8, 2018

of vein of Galen "aneurysms" was first proposed by Jaeger et al in $1937 .{ }^{5}$ In current understanding, the word, "aneurysms," is also an description error. This tendency is arbitrary since the word is derived from the Greek aneurynein, that is, to dilate. Therefore, the use of a "venous aneurysms" is etymologically legitimate rather than a misnomer. ${ }^{6}$

Endovascular embolization is generally considered to be the first-line therapeutic option. A meta-analysis performed by Yan et $\mathrm{al}^{7}$ revealed that the mortality rate of embolized patients decreased from 17 to $12 \%$ from 1980s to 2000s. But the management is still challenging. This article reviewed the pathogenesis, classification, clinical manifestations, imaging of VGAM, and summarized the key points of endovascular embolization to improve the rate of treatment and prognosis for VGAM.

\section{Pathogenesis}

The persistent arteriovenous shunting from primitive choroidal vessels into the MProsV is the predominant pathogenesis of VGAM, which occurs at the 6th to 11th week of gestation, after development of the circle of Willis ( - Fig. 1). The posterior part

Copyright @ 2019 by Georg Thieme Verlag KG, Stuttgart . New York
DOI https://doi.org/ 10.1055/s-0038-1635108. ISSN $1304-2580$. 

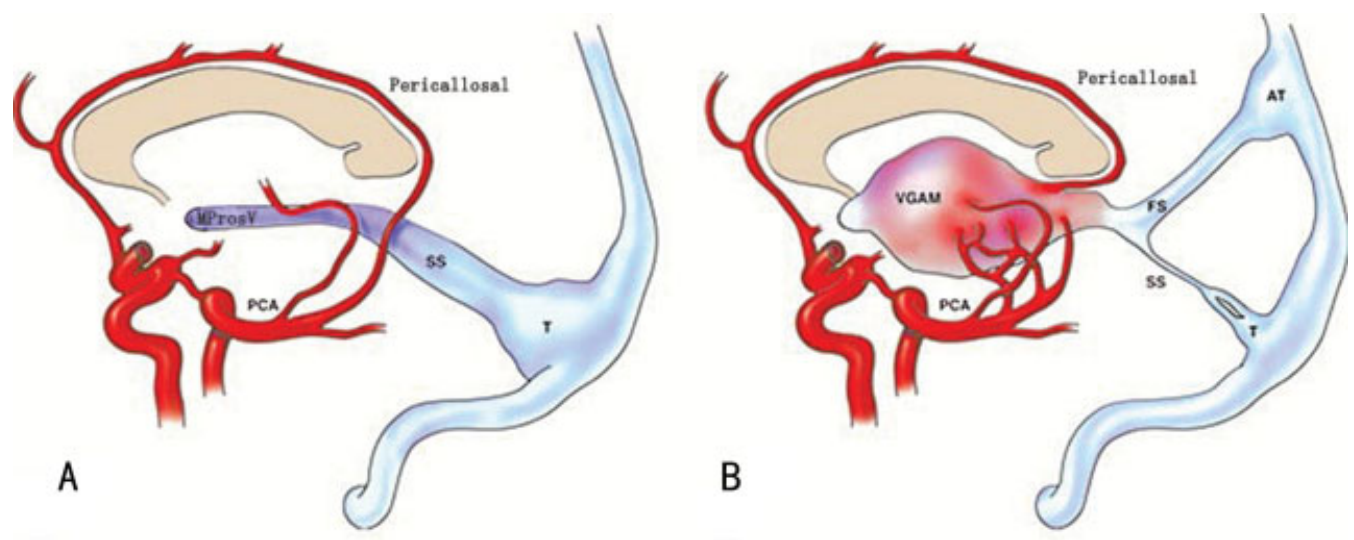

Fig. 1 The formation of VGAM. ${ }^{25}$ (A) Normal vessel structure between the pericallosal arteries and the PCA is present in embryonic period. (B) The abnormal high-output arteriovenous connection contributes to aneurysmal dilation of the MProsV, which leads to the formation of VGAM. This connection drains into the SS and subsequently into T. In addition, it also bloods into the FS and then into the AT when the SS is absent, hypogenetic, or stenotic. Reproduced with permission from Mortazavi et al. ${ }^{25} \mathrm{AT}$, accessory torcula; FS, falcine sinus; MProsV, median prosencephalic vein; MRI, magnetic resonance imaging; PCA, posterior cerebral arteries; SS, straight sinus; T, trocula; VGAM, vein of Galen aneurysmal malformation.

of the MProsV persists as the vein of Galen, while the anterior portion regresses in parallel with the formation of the internal cerebral veins. The remnants of the MProsV then join the internal cerebral veins to form the vein of Galen, which may cause the existence of connection between the VGAM and the deep venous system. Raybaud and Strother ${ }^{8}$ identified the dilated venous structure as the MProsV at first. The arteriovenous connection between primitive choroidal vessels and MProsV leads to hemodynamic abnormalities, which results in the obstruction of embryologic vein regression and the development of vein of Galen. Subsequently, the high-output arteriovenous connection contributes to venous hypertension and aneurysmal dilation of MProsV. Besides, stenosis of dural sinuses is another cause of the dilatation, resulting from the rapid and turbulent flow caused by the arteriovenous connection.

The drainage of the malformation is toward the straight sinus, and it also drains into sagittal sinus through the persistent falcine sinus, in this case the straight sinus is absent, hypogenetic or stenotic. ${ }^{9}$ The cases of VGAM with persistent falcine sinus have been reported previously by us ${ }^{10}$ ( - Fig. $\mathbf{2}$ ). The arteriovenous deformation is supplied by a variety of arterial feeding vessels including subependymal network originating from the posterior circle of Willis, thalamoperforating arteries, choroidal arteries, and the limbic arterial arch. ${ }^{4}$ It is located in the cistern of velum interpositum as well as the quadrigeminal cistern, and there is no connection between the malformation and the deep venous system, which has been considered traditionally. However, this theory has been challenged in recent literature reports. ${ }^{11-13}$ In these studies, the drainage of the malformation into the deep venous system has been confirmed by follow-up imaging, including internal cerebral veins, straight sinus, falcine sinus, basal vein of Rosenthal, and inferior sagittal sinus.

The genetic susceptibility to VGAM is still unclear, while there are some potentially causative genes reported in
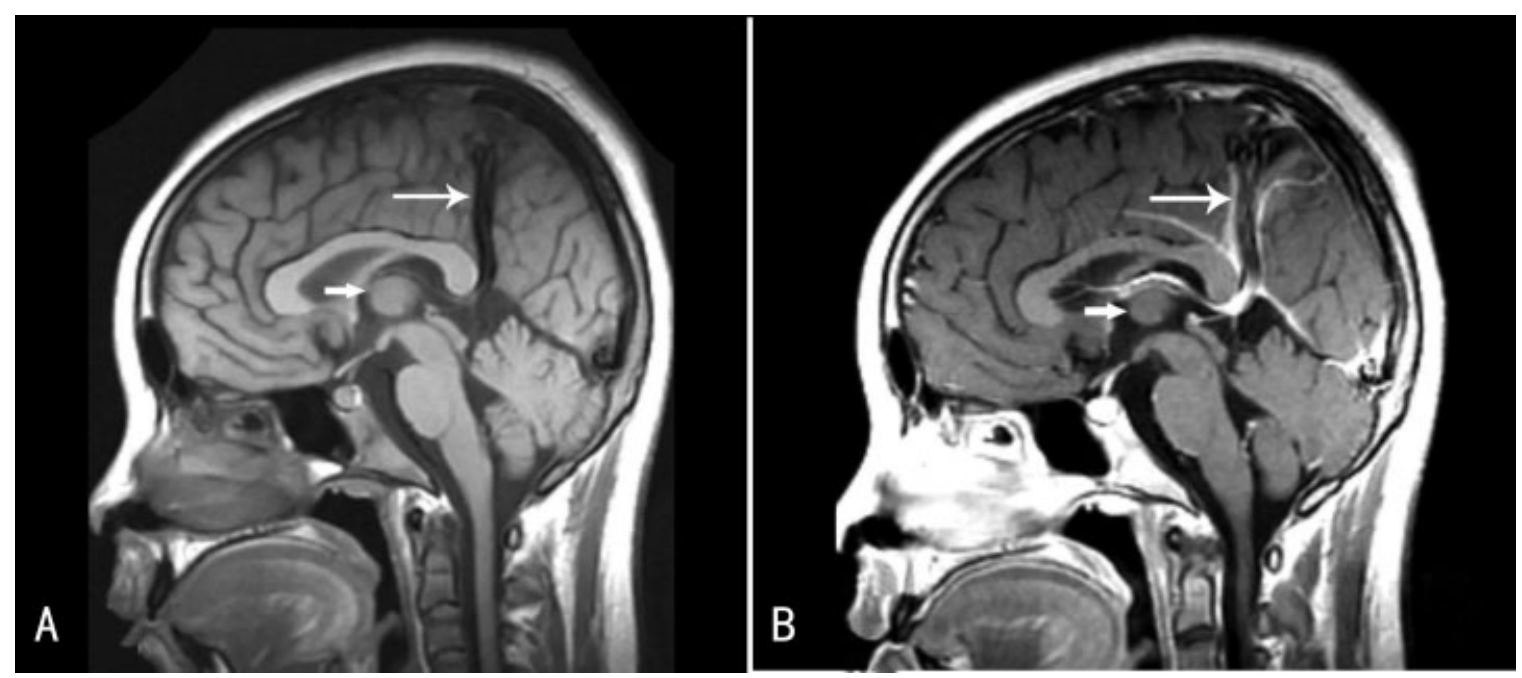

Fig. 2 Cranial sagittal MRI in a patient with VGAM reveals a dilated MProsV (short arrow) connected with a persistent falcine sinus (long arrow) blooded into the sagittal sinus and the absence of straight sinus on T1WI (A) and T2WI (B). MProsV, median prosencephalic vein; MRI, magnetic resonance imaging; VGAM, vein of Galen aneurysmal malformation; WI, weighted imaging. 
association with this condition. Revencu et al $^{14}$ identified RASA1 gene mutation in two patients with VGAM. Chida et $\mathrm{al}^{15}$ reported one variant of ACVRL1 in a case with VGAM. Tsutsumi et $\mathrm{al}^{16}$ published a patient with VGAM carrying a mutation in the ENG gene encoding endoglin; this patient presented with a family history of hereditary hemorrhagic telangiectasia and the authors hypothesized the gene might be etiologically related to VGAM. Additionally, Xu et al ${ }^{17}$ reported a familial VGAM in an adult female patient with VGAM, who had a history of a stillbirth pregnancy caused by VGAM. However, the relationship between genetic factors and VGAM needs to be further investigated.

\section{Classification}

\section{Vein of Galen Aneurysmal Malformation}

The first classification of VGAM was proposed by Litvak et $\mathrm{al}^{18}$ in 1960 . There are two most widely accepted classifications described by Lasjaunias and Yasargil, respectively (-Table 1). Based on the age at presentation and angioarchitecture of the fistulae, Lasjaunias et al ${ }^{19}$ divided VGAM into two types: choroidal type and mural type (-Fig. 3). ${ }^{20}$ The choroidal type is the most common type accounting for 56 to $76 \%$ of all VGAMs and is common in males. ${ }^{21}$ It mainly occurs

Table 1 Classification of VGAM

\begin{tabular}{|l|l|}
\hline Lasjaunias' classification & Yasargil's classification \\
\hline Mural type & Type I \\
\hline Choroidal type & Type II \\
\cline { 2 - 2 } & Type III \\
\hline & $\begin{array}{l}\text { Type IV } \\
\text { (type IVA, type IVB, type IVC) }\end{array}$ \\
\hline
\end{tabular}

Abbreviation: VGAM, vein of Galen aneurysmal malformation. in neonates, ${ }^{22}$ characterized by congestive heart failure due to a high flow fistula. In choroidal type, multiple arterial feeders like a nidus shunt into the anterior aspect of MProsV. The feeder vessels mostly come from the choroidal arteries, involving the anterior and posterior choroidal, anterior cerebral, as well as quadrigeminal and thalamoperforating arteries occasionally. ${ }^{23}$ In mural type, one or more arteriovenous fistulae (AVF) shunt into the inferolateral margin in the wall of MProsV with lower flow. The arterial feeders arise from unilateral or bilateral quadrigeminal arteries and posterior choroidal arteries. Clinically, it is common in infants and children associated with the symptoms of macrocephaly, hydrocephalus, and developmental delay. Due to slow flow and few fistulae, it has a better prognosis, and thrombosis is more common in this type compared with choroidal type.

Yasargil $^{24}$ dichotomized VGAM into four types according to whether the malformation is a pure AVF (types I-III) or an arteriovenous malformation (AVM) with or without associated AVF (types IVA-C), and the exact origin of the feeding arteries. Type I is a pure AVF between posterior cerebral artery (P4 and its branches), anterior or posterior pericallosal arteries, and the vein of Galen. Type II is the fistulous connection between the thalamoperforators (basilar and P1 segment) and the vein of Galen. Type III is a mixture of type I and II, which is the commonest type. Type IV comprises three subtypes. Type IVA is similar to type IVB. Both types IVA and IVB are aneurysmal dilation of the vein of Galen caused by shunting from an adjacent thalamic and mesencephalic AVM, respectively. Type IVC is a thalamomesencephalic or mesodiencephalic plexiform malformation along with an adjacent and separate cisternal AVF to the vein of Galen. ${ }^{25,26}$ Though the Yasargil's classification is classic and widely recognized, there are several deficiencies. The clinical presentation and outcome are not involved in the Yasargil's classification.
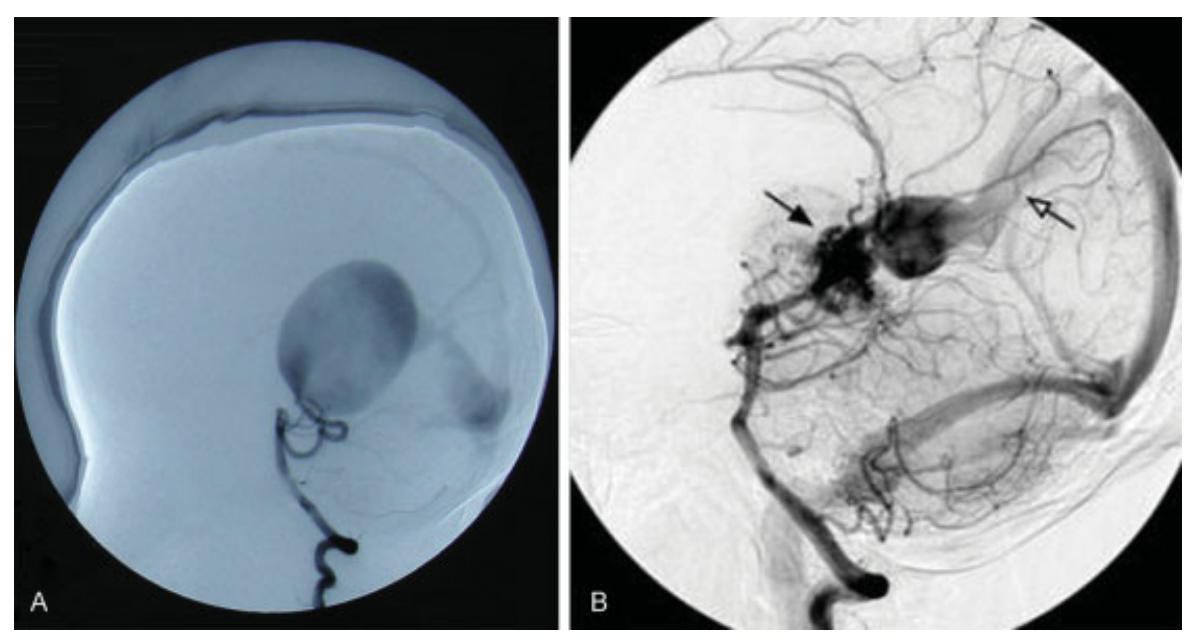

Fig. 3 (A) Mural type of VGAM. MR angiography displays an AVF directly into the wall of the venous pouch. Note the drainage of the malformation into the stenosis straight sinus; (B) Choroidal type of VGAM. In comparison with mural type, MR angiography of choroidal type shows an extensive arterial network like a nidus centered in the region of the quadrigeminal plate cistern (closed arrow), flowing into the malformation and primitive falcine sinus (open arrow). ${ }^{20}$ Reproduced with permission from Triffo et al. ${ }^{20}$ AVF, arteriovenous fistula; MR, magnetic resonance; VGAM, vein of Galen aneurysmal malformation. 


\section{Vein of Galen Aneurysmal Dilatation}

Vein of Galen aneurysmal dilatation (VGAD) refers to the dilated vein of Galen arising from the drainage of an AVM into the true vein of Galen rather than the precursor of the vein of Galen. It belongs to the group of dura AVM. Different from VGAM, it is a real malformation of Galen vein and contacted with the deep venous system. The arterial supply comprises the internal carotid artery, meningeal branches of internal and external carotid artery, normal sinus, the drainage from Galen vein into brain parenchyma, and mesencephalic or diencephalic AVM. ${ }^{27}$ Based on the source of abnormal blood, VGAD can be differentiated into (1) solid type, (2) varicose type, and (3) dura mater type. According to the shunt location of VGAD, lizuka et $\mathrm{al}^{28}$ proposed a new anatomical classification, involving (1) ventricular type, (2) cisternal type, and (3) parenchymal type.

\section{Vein of Galen Varices}

Vein of Galen varices is the varicose dilatation of the Galen vein without an arteriovenous shunt. There are two types of the vein of Galen varices in children. The first type is a transient dilatation of the Galen vein accompanied with heart failure caused by other origins. This type is asymptomatic and cardiac function is improved along with the disappearance of the dilatation. The second type occurs when flowing a complete hemisphere into the deep venous system. It is also asymptomatic, but the venous ischemia disorders may occur as a result of insufficient venous drainage. $^{25}$

\section{Clinical Manifestations}

Clinical presentations vary with the age of onset and vascular architecture. The main manifestations include congestive heart failure, hydrocephalus, and neurological symptoms. In 1964 , Gold et $\mathrm{al}^{29}$ proposed a clinical classification based on the age of onset, including the group of neonates, infants as well as children and adults. In neonates, the predominant clinical manifestation is represented by serious congestive heart failure. The prognosis is extremely poor with high mortality, and choroidal type is common in this group. During infancy, clinical presentations mainly consist of hydrocephalus, macrocephaly, seizures, developmental delay, and mild heart failure. The mechanisms causing hydrocephalus include hypertension, impaired cerebrospinal fluid reabsorption, and compression of mesencephalic aqueduct. Mural type usually occurs in this group. In children and young adults, the symptoms consist of headache, hydrocephalus, seizure, neural dysfunction, and subarachnoid hemorrhage. Both choroidal and mural types are observed in this group. In addition, there are some rare clinical manifestations reported in the literature, which include galactosemia, ${ }^{30}$ abnormal movement (e.g., chronic asymmetric tremor), ${ }^{31}$ a pulsatile right-sided neck swelling due to tortuous carotid artery and bilateral dilatation of neck veins, $^{32}$ jugular bulb stenosis, ${ }^{33}$ dilated scalp veins, and tonsillar prolapse. But the relationship between these clinical manifestation and VGAM needs to be further confirmed.
Additionally, Lasjaunias et $\mathrm{al}^{22}$ recommended the Bicêtre neonatal evaluation score system, which takes into account neurological, cardiac, respiratory, renal, and hepatic functions (-Table 2). It helps to estimate the comprehensive symptoms of patients with VGAM and assists with the therapeutic decision. A score of less than 8 indicates a poor outcome needing expectant treatment. An emergency endovascular treatment is advised relating to a score of 8 to 12. The embolization can be delayed until 5 months of age associated with a score of 13 to 21 . Besides, the evaluation of the neurocognitive status could be performed using the Denver test and the Brunet-Lézine test. ${ }^{34}$

\section{Imaging}

VGAM is one of the diseases mostly diagnosed prenatally with the proportion of approximately $40 \% .{ }^{35}$ However, a retrospective analysis of 25 patients with VGAM conducted by Geibprasert et $\mathrm{al}^{36}$ showed there was no relevance between early prenatal diagnosis and the follow-up outcome. But it assisted in the decision of therapy plan and facilities. Prenatal diagnosis is usually made during the third trimester of pregnancy by ultrasonography according to the visualization of an anechogenic or hypoechogenic round or ovoid structure with regular borders located in the midline of the posterior part of the third ventricle. Enough dilatation of the malformation is required if it can be detected on the first- or even second-trimester ultrasound $^{36}$ and the conformation of the antenatal diagnosis is usually performed by color Doppler imaging and magnetic resonance imaging (MRI). There is an antenatal VGAM classification including isolated VGAM, when VGAM is the only manifestation and associated VGAM, when VGAM is associated with cardiac and neurological abnormalities. ${ }^{37}$ However, it might be challenged in the future research. Termination of pregnancy should be performed when fetal hydrops and serious heart failure occur.

The chest radiograph shows cardiomegaly resulting from congestive heart failure. Brain radiograph may display a rim of calcification within the wall of the aneurysmal sac, which is considered to be a poor indicator associated with the tendency of subsequent thrombosis. ${ }^{25}$ Cranial computed tomography (CT) usually displays a spherical mass located in the quadrigeminal cistern or the cistern of velum interpositum. Dilated ventricular system, periventricular white matter hypodensities, and diffuse cerebral atrophy are usually associated MRI findings (-Fig. 4). MRI has the advantage to accurately demonstrate the location of the lesion, vascular architecture, and status of vessel drainage in the VGAM malformation (-Fig. 5); furthermore, the position and identity of major arterial trunks, primary branches as well as secondary branches feeding the fistula are better recognized on brain MRI than on cranial CT. ${ }^{38}$ Additionally, parenchymal changes including focal encephalomalacia and diffuse brain volume loss can also be visible in CT and MRI, which are considered to be predictors of poor outcome. ${ }^{36}$ Angiography (including MR angiography and CT angiography) remains the gold standard for the diagnosis. It has advantages in revealing the site, size, 
Table 2 Bicêtre neonatal evaluation score ${ }^{22}$

\begin{tabular}{|l|l|l|l|l|l|}
\hline Points & Cardiac function & Cerebral function & Respiratory function & Hepatic function & Renal function \\
\hline 5 & Normal & Normal & Normal & - & - \\
\hline 4 & $\begin{array}{l}\text { Overload, no medi- } \\
\text { cal treatment }\end{array}$ & $\begin{array}{l}\text { Subclinical, isolated } \\
\text { EEG abnormalities }\end{array}$ & $\begin{array}{l}\text { Tachypnea, finishes } \\
\text { bottle }\end{array}$ & - & - \\
\hline 3 & $\begin{array}{l}\text { failure, stable with } \\
\text { medical treatment }\end{array}$ & $\begin{array}{l}\text { Nonconvulsive inter- } \\
\text { mittent neurological } \\
\text { signs }\end{array}$ & $\begin{array}{l}\text { Tachypnea, does not } \\
\text { finish bottle }\end{array}$ & $\begin{array}{l}\text { No hepatomegaly, } \\
\text { normal hepatic } \\
\text { function }\end{array}$ & Normal \\
\hline 2 & $\begin{array}{l}\text { Failure, not stable } \\
\text { with medical } \\
\text { treatment }\end{array}$ & $\begin{array}{l}\text { Isolated convulsion } \\
\text { Ventilation }\end{array}$ & $\begin{array}{l}\text { Assisted ventilation, } \\
\text { normal saturation } \\
\text { FlO } 2<25 \%\end{array}$ & $\begin{array}{l}\text { Hepatomegaly, } \\
\text { normal hepatic } \\
\text { function }\end{array}$ & Transient anuria \\
\hline 1 & $\begin{array}{l}\text { Seizures } \\
\text { cal therapy }\end{array}$ & $\begin{array}{l}\text { Assisted ventilation, } \\
\text { normal saturation } \\
\text { FlO } 2>25 \%\end{array}$ & $\begin{array}{l}\text { Moderate or transi- } \\
\text { ent hepatic } \\
\text { insufficiency }\end{array}$ & $\begin{array}{l}\text { Unstable diuresis } \\
\text { with treatment }\end{array}$ \\
\hline 0 & Permanent neurologi- & $\begin{array}{l}\text { Assisted ventilation, } \\
\text { desaturation }\end{array}$ & $\begin{array}{l}\text { Abnormal coagula- } \\
\text { tion, elevated } \\
\text { enzymes }\end{array}$ & Anuria \\
\hline
\end{tabular}

Abbreviations: EEG, electroencephalogram; $\mathrm{FIO}_{2}$, fractional inspired oxygen.

Maximal score $=5$ (cardiac) +5 (cerebral) +5 (respiratory) +3 (hepatic) +3 (renal) $=21$.

Source: Reproduced with permission from Lasjaunias et al. ${ }^{22}$

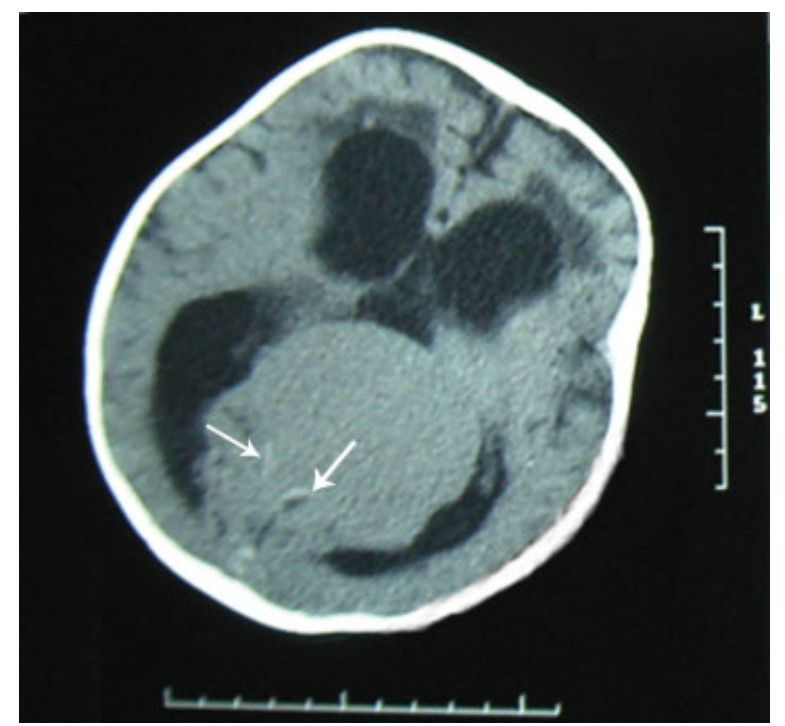

Fig. 4 Axial CT scan of brain in a patient with VGAM reveals a large homogeneous, well-defined spherical mass associated with dilated third and lateral ventricles and hydrocephalus because of the compression of the aqueduct, as well as periventricular white matter hypodensities (arrows). CT, computed tomography; VGAM, vein of Galen aneurysmal malformation.

morphology, and abnormal flow dynamics of vessels ( - Fig. 6). Similarly, it better shows the small feeders supplying the fistula, as well as the dynamic aspects of the venous drainage into the normal brain and hemodynamics of the arteriovenous shunt. $^{26,35}$ Strategies for the decision of treatment can be made according to the evidence on angiography. In future applications, four-dimensional flow MRI is probably useful in the management and monitoring intracranial hemodynamic alteration during embolizations, to estimate the efficacy and risk of reperfusion complications. ${ }^{39}$ Wu et al ${ }^{40}$ indicated that it assisted in detecting the arteriovenous shunt flow, cerebral vessel inflow, and cerebral flow redistribution after embolizations during staged embolizations of six patients with VGAM.

The spontaneous thrombosis of VGAM is rare and the underlying causal mechanism is not entirely understood. There are multifactors described including the alteration of hemodynamics (slow flow, increased pressure, or turbulence), vascular spasm, vascular proliferation, and regressive atherosclerotic changes in the vessels. ${ }^{41,42}$ The ventricular shunting and the use of contrast media for angiography are also considered to be correlated with the thrombosis of VGAM. ${ }^{41}$ The imaging investigation can well demonstrate the features of thrombosis. On CT, it reveals heterogeneous signal associated with calcified capsule occasionally. Contrast-enhanced CT shows a central thrombus and peripheral circulating blood along the wall of the sac, called "targetsign." ${ }^{26}$ MRI of the thrombosis VGAM displays extracellular methemoglobin in the central part and hemosiderin in the peripheral part of lesion. ${ }^{43}$

\section{Management}

The purpose of therapy is various according to the age of onset. In newborns, the goal of therapy is mainly the correction of heart failure, while in older children the aim is to improve the neurological symptoms. ${ }^{4}$ It is advised that the therapy outcome is to reverse the pathophysiologic effects caused by the arteriovenous deformation rather than to obtain a complete normal morphologic appearance. ${ }^{44}$ The management of VGAM includes a combination of surgical approaches, endovascular treatments, radiosurgery, and conservative treatments. Endovascular embolization is the preferred treatment and others are considered to be the complementary options, when embolization is limited. 

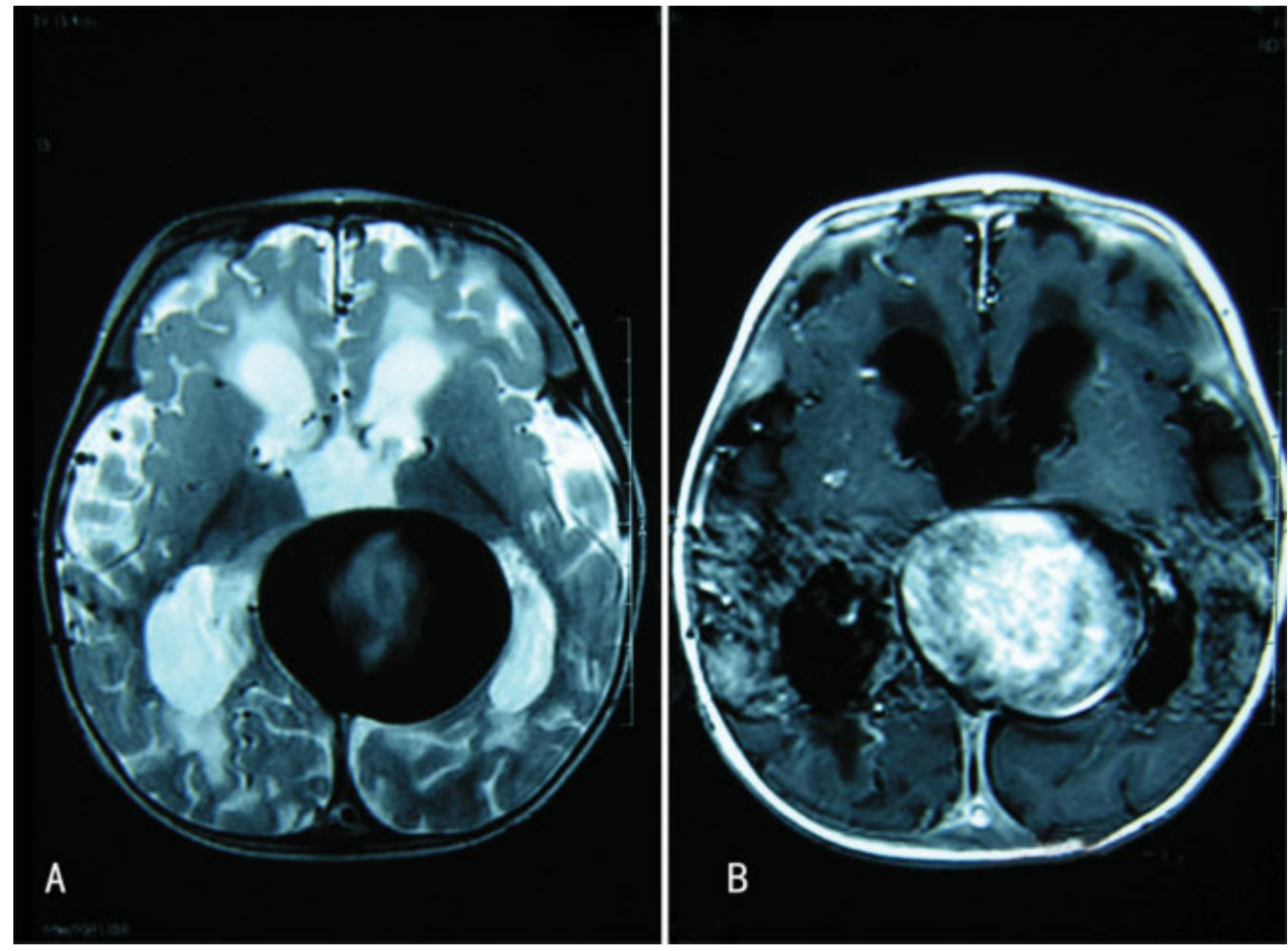

Fig. 5 Cerebral MRI in axial of a patient with VGAM shows a well-defined midline round mass within the pineal region accompanied with the dilatation of lateral and third ventricles on T1WI (A) and T2WI (B). MRI, magnetic resonance imaging; VGAM, vein of Galen aneurysmal malformation; WI, weighted imaging.
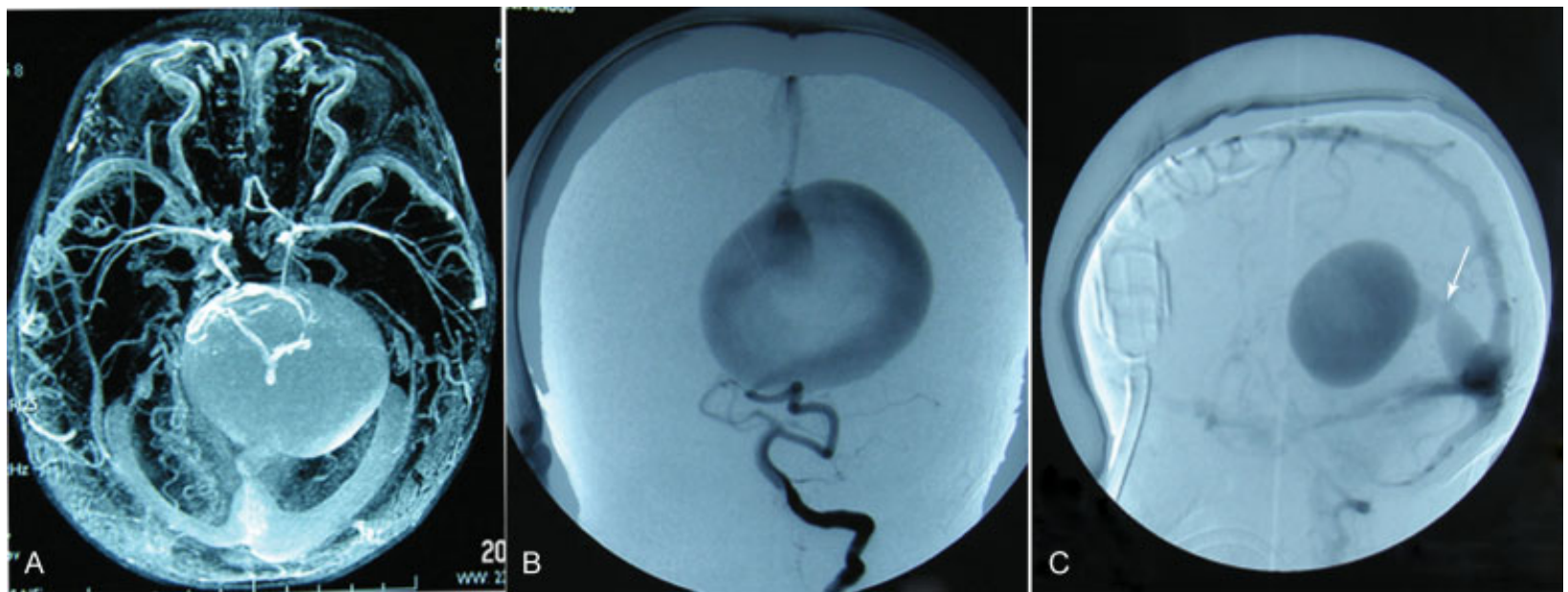

Fig. 6 (A) MR angiography shows the dilated aneurysmal mass with some feeding vessels which drains into the straight sinus. (B) Vertebral artery angiography displays the dilated median prosencephalic vein blooding into the straight sinus, which belongs to the mural type of VGAM. (C) Lateral view reveals the stenosis of straight sinus (arrow) draining directly into the superior sagittal sinus. MR, magnetic resonance; VGAM, vein of Galen aneurysmal malformation.

\section{Surgery and Radiosurgery}

Though the method of surgery is widely used, the complete resection and surgical clipping of the vessels are still challenging with higher morbidity and mortality. The problem is associated with surgery including the deep location of the lesion, high-flow shunt, complex vascular architec- ture, and poor tolerance in infants. Therefore, surgery is usually considered as a complementary approach when embolization is failed. Additionally, ventricular shunting may exacerbate the cerebral venous hypertension and brain ischemia due to the alteration of venous drainage. Hence, ventricular shunting should be performed after 

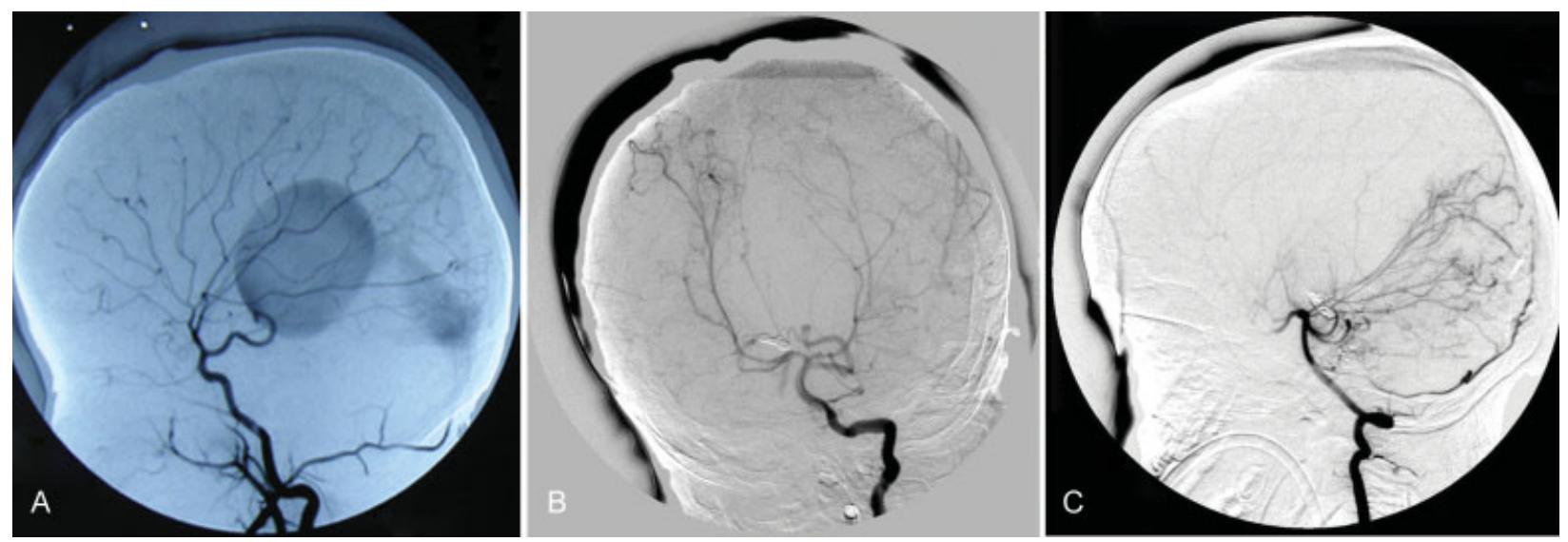

Fig. 7 Carotid angiogram of a patient with VGAM displays a dilated aneurysmal malformation (A). Post-embolization angiogram shows the complete occlusion of the malformation using Guglielmi coils in anteroposterior (B) and lateral (C) views. VGAM, vein of Galen aneurysmal malformation.

embolization. ${ }^{22,26}$ Similarly, the approach of Gamma knife surgery is also a complementary alternative since it does not reduce the size of the lesion immediately. Stereotactic radiotherapy may have an effect on some patients with VGAM, but its effect is still not clear. Besides, there is controversy about the lesion to the development of brain.

\section{Endovascular Therapy}

The first case treated by embolization was reported in 1950 by Davis. ${ }^{45}$ With the development of endovascular treatment, the mortality rate has dropped from $60-82 \%$ to $11 \%{ }^{46}$ The goal of endovascular therapy is to reduce intracranial shunting or even occlude all the fistulae (-Fig. 7). In fact, total obliteration is not necessary because a reduction in one-third to half of the shunt is enough to correct the clinical symptoms. ${ }^{47}$ Recently, a meta-analysis showed the predominant complications of endovascular treatment consisted of cerebral vessel perforation, hemorrhage, cerebral ischemia, hydrocephalus, and leg ischemia. ${ }^{7}$ The prevention of complications depends on proper super selective embolization, selection of embolic material and exact technique, as well as preservation of normal cerebral deep venous drainage. Additionally, the existence of normal drainage between deep venous system and VGAM should be considered before embolization in case of the occurrence of adverse effects to the normal cerebral vessel after endovascular management. Although it is difficult to be seen through angiograms or noninvasive imaging presumably due to technical factors and hemodynamics, the drainage is a critical element of the treatment planning. ${ }^{11}$

There are two options of embolization including transarterial and transvenous approach, of which the transarterial route is preferred. Umbilical artery approach can be used for embolization in the early neonatal period, and the femoral artery is an alternative route when the umbilical artery is not available. As for transvenous approach, there is a controversy regarding the outcome of transvenous embolization. In previous literature, it was considered to be not feasible due to increased morbidity. In recent article, Orlov et $\mathrm{al}^{48}$ considered it was a safe and effective salvage method for VGAM with restricted transarterial access. Besides, Meila et $\mathrm{al}^{49}$ described a combined transvenous and transarterial approach, called kissing microcatheter technique. It was considered to be a safe method with lower complication rate and the overall outcome can be improved, particularly in the neonate with congestive heart failure. The embolic agents comprise coils, microballoons, $\mathrm{N}$-butyl-cyanoacrylate (NBCA), Onyx liquid, and ethylene vinyl alcohol copolymer. In choroidal type of VGAM, Onyx is recommended because of the advantage of more definitive and stable occlusion. In mural type, NBCA is a preferred embolic material due to the properties of quick precipitation and adhesion to vessel. ${ }^{48}$ In addition, Joo et $\mathrm{al}^{42}$ first reported a patient with a mural-type VGAM who was successfully treated using the Micro Vascular Plug system, which may be a potential available option.

The staged embolization is recommended to minimize the occurrence of complications such as a normal perfusion pressure breakthrough phenomenon or a multiple venous thrombosis. ${ }^{11}$ The interval is usually 3 to 6 months. ${ }^{4,23}$ There is a new classification scoring system for the decision of treatment proposed by Mortazavi et $\mathrm{al}^{25}$ which combines arterial feeders with clinical symptoms and age (-Table 3). Embolization is not urgent and one stage of embolization is suggested for patients with a score of 0 to 1 . Urgent embolization and multiple stages of treatment are recommended when the score is 2 points. Embolization in multiple stages or palliative treatment is advised for patients with a score of 3 .

The time of endovascular management depends on the clinical symptom and is preferably at the age of 5 to 6 months for maximum safety and efficacy of treatment. ${ }^{26}$ However, symptoms related to the possible progression of the heart failure and the potential development of hydrocephalus need to be closely followed up ${ }^{50}$. The decision of management can be evaluated by the Bicêtre scoring system proposed by 
Table 3 New classification system proposed by Mortazavi et al ${ }^{25}$

\begin{tabular}{|l|l|l|}
\hline & Score & $\mathbf{1}$ \\
\hline Parameter & $\mathbf{0}$ & $\begin{array}{l}\text { Any of the following feeders: P1-2, } \\
\text { thalamoperforators, choroidal, basilar }\end{array}$ \\
\hline Arterial feeders & $\begin{array}{l}\text { Any feeders other than P1-2, } \\
\text { thalamoperforators, choroidal, basilar }\end{array}$ & Heart failure \\
\hline Clinical symptoms & No heart failure & $<5$ months \\
\hline Age & $\geq 5$ months & $<$
\end{tabular}

Source: Reproduced with permission from Mortazavi et al. ${ }^{25}$

Alvarez et $\mathrm{al}^{4}$ (-Table $\mathbf{2}$ ). A score of more than 12 suggests the clinical symptom is stable and it is better to prolong therapy until the age of 5 to 6 months. Endovascular embolization is recommended when a score is between 8 and 12 . There is no indication for embolization associated with a score of less than 8 .

VGAD is the pathological dilatation of Galen vein due to the stenosis or obstruction of the outflow. The degree of dilatation is varied with the extent of stenosis. So, the treatment of VGAD with high flow is mainly planned embolization or stereotactic radiotherapy. For low level VGAD, intravascular embolization is the major approach of management. ${ }^{27}$ It is associated with a good prognosis in comparison with VGAM because VGAM has high morbidity and mortality due to refractory high-output heart failure and neurological damage. ${ }^{51}$ As for the vein of Galen varices, it has lower hemorrhage risk and better outcome. The adverse consequence may occur as a result of an inappropriate surgical or interventional management. Conservative treatment is recommended for patients with stable symptoms, ${ }^{52}$ and close follow-up with imaging investigations is essential.

\section{Prognosis}

Without treatment, more than $90 \%$ of patients with VGAM die in the neonatal and infant period. A meta-analysis about the outcome and complications of endovascular embolization for VGAM revealed the proportion of the good outcome increased from 49 to $70 \%$ from 1980 s to 2000 s. $^{7}$ But the morbidity and mortality are still very high. There are some factors that correlated with the clinical outcome involving embolization technology, clinical presentation (multiorgan failure and neurological symptoms), and imaging findings (extensive encephalomalacia, arterial steal, parenchymal calcification, and high-flow multifeeder shunts). ${ }^{36}$ Additionally, the choroidal type of VGAM has worse prognosis than mural type. Agarwal et $\mathrm{al}^{53}$ retrospectively analyzed 36 patients with VGAM and concluded that jugular atresia was significantly associated with poor outcome. A systematic review conducted by Yan et $\mathrm{al}^{54}$ showed the outcome was good in the patient with an early spontaneous thrombosis, while the outcome was poor in the late stages of the VGAM with spontaneous thrombosis.
The main sequela of VGAM is represented by permanent neurological deficit with intellectual disability and epilepsy. The evaluation of therapy outcome in patients with VGAM can be performed by the system of Bicêtre admission and outcome score proposed by Lasjaunias et $\mathrm{al}^{22}$ ( - Table 4 ). This scoring system can help to estimate the effect of clinical treatment, contribute to correct the therapy approaches, and improve the level of management of VGAM.

In this study, we performed a literature retrospective of relevant articles in the recent 15 years using the database of PubMed (https://www.ncbi.nlm.nih.gov/pubmed) with the key words "vein of Galen aneurysmal malformation" or "VGAM." The detail information was collected, including age, sex, types of VGAM, clinical feature, treatment, and outcome (-Tables 5 and $\mathbf{6}$ ). A total of 43 patients ( 36 children and 7 adults) were enrolled. We found that the mortality of VGAM was still high. The prognosis of VGAM in adult was better than children, and the mural type was associated with a good outcome compared with choroid type.

Table 4 Bicetre admission and outcome score ${ }^{22}$

\begin{tabular}{|l|l|}
\hline Score & Condition \\
\hline 5 & Normal (N) \\
\hline 4 & $\begin{array}{l}\text { Minimal non-neurological symptoms, not } \\
\text { treated (MS), and/or asymptomatic } \\
\text { enlargement of the cardiac silhouette }\end{array}$ \\
\hline 3 & $\begin{array}{l}\text { Transient neurological symptoms, not treated } \\
\text { (TNS), and/or asymptomatic cardiac overload } \\
\text { under treatment }\end{array}$ \\
\hline 2 & $\begin{array}{l}\text { Permanent minor neurological symptoms, } \\
\text { mental retardation of up to 20\%, nonperma- } \\
\text { nent neurological symptoms under treatment } \\
\text { (MNS), normal school with support, and/or } \\
\text { cardiac failure stabilized with treatment }\end{array}$ \\
\hline 1 & $\begin{array}{l}\text { Severe neurological symptoms, mental } \\
\text { retardation of more than 20\% (SNS), } \\
\text { specialized school and/or cardiac failure } \\
\text { unstable despite treatment }\end{array}$ \\
\hline 0 & Death(D) \\
\hline
\end{tabular}

Note: Does not apply to neonates.

Source: Reproduced with permission from Lasjaunias et al. ${ }^{22}$ 
Table 5 Literature review of clinical outcomes after treatment of VGAM in children

\begin{tabular}{|c|c|c|c|c|c|}
\hline Authors & Age/sex & Type & Clinical features & Treatment & Outcome \\
\hline Pop et $\mathrm{al}^{55}$ & $11 \mathrm{mo} / \mathrm{M}$ & Mural & IHC, DD & $\begin{array}{l}\text { Femoral TA } \\
\text { Embolization }\end{array}$ & Normal \\
\hline Gupta et al ${ }^{26}$ & $1 \mathrm{y} / \mathrm{M}$ & Mural & MC, ASD occipital bruit & Embolization (TA) & Normal \\
\hline Triffo et $a^{20}$ & Neonate/M & Mural & PD, CHF, RD & Embolization (TA), GKRS & Normal \\
\hline Jones et $\mathrm{al}^{56}$ & Neonate/F & Mural & PD, Mild CHF & Embolization (TA) & Normal \\
\hline Ellis et $\mathrm{al}^{57}$ & $5 \mathrm{mo} / \mathrm{M}$ & Mural & MC, cranial bruit & Embolization & Normal \\
\hline Ellis et $\mathrm{al}^{57}$ & Neonate/F & Mural & $\mathrm{PD}, \mathrm{CHF}$ & Embolization & Normal \\
\hline Joo et $\mathrm{al}^{42}$ & $4 \mathrm{mo} / \mathrm{F}$ & Mural & IHC, DFV, NSC, lethargy & Embolization (TA) & Normal \\
\hline Gupta et al ${ }^{26}$ & $3 y / M$ & Mural & $\mathrm{H}$ & Embolization (TV and TA) & Died \\
\hline Filippi et $a^{30}$ & Neonate/M & Mural & $\mathrm{PD}, \mathrm{H}, \mathrm{CD}, \mathrm{HF}, \mathrm{HM}$ & Embolization (TA) & Died \\
\hline Orlov et $\mathrm{al}^{48}$ & Neonate/M & Mural & $\mathrm{PD}, \mathrm{CHF}$ & Embolization (TA) & Sz, mild DD \\
\hline Ellis et $\mathrm{al}^{57}$ & $21 \mathrm{mo} / \mathrm{F}$ & Mural & MC, cranial bruit & Embolization & LSH, ANP, DVA \\
\hline Heuer et al ${ }^{50}$ & Neonate/M & Mural & RVH, RVD & None & Improved \\
\hline Cai et $\mathrm{at}^{58}$ & $15 \mathrm{mo} / \mathrm{M}$ & Mural & Sz, DFV, IHC & Embolization (TV) & Improved \\
\hline Kong we al ${ }^{59}$ & Neonate/M & Mural & PD, H, IVH, V & Embolization (TA) & Improved \\
\hline Orlov et al $^{48}$ & Neonate/M & Choroidal & PD, no symptom & Embolization (TA) & Normal \\
\hline Tsutsumi et al ${ }^{16}$ & Neonate/M & Choroidal & $\begin{array}{l}\mathrm{CD}, \mathrm{HM}, \mathrm{HF} \text {, cardiac } \\
\text { bruit, }\end{array}$ & Embolization (TA) & Normal \\
\hline Ellis et $\mathrm{al}^{57}$ & Neonate/M & Choroidal & CHF, cranial bruit & Embolization & Normal \\
\hline Heuer et al ${ }^{50}$ & $5 \mathrm{~d} / \mathrm{M}$ & Choroidal & $\mathrm{HF}$ & Embolization & Normal \\
\hline Heuer et $\mathrm{al}^{50}$ & $7 d / F$ & Choroidal & $\mathrm{HF}$ & Embolization & Normal \\
\hline Heuer et $\mathrm{al}^{50}$ & $31 \mathrm{mo} / \mathrm{M}$ & Choroidal & Mild LVH hemorrhage & Embolization & Normal \\
\hline Heuer et $\mathrm{al}^{50}$ & $6 \mathrm{mo} / \mathrm{M}$ & Choroidal & None & Embolization & Normal \\
\hline Heuer et $\mathrm{al}^{50}$ & Neonate/M & Choroidal & Mild HF & Embolization & Normal \\
\hline Heuer et al ${ }^{50}$ & Neonate/F & Choroidal & $\mathrm{HF}$ & Embolization & Died \\
\hline Heuer et al ${ }^{50}$ & $6 \mathrm{~d} / \mathrm{M}$ & Choroidal & HF, RVH, RVD & Embolization & Died \\
\hline Heuer et $\mathrm{al}^{50}$ & Neonate/M & Choroidal & HF, PDA, Sz, ischemia & Embolization & Died \\
\hline Jones et $\mathrm{al}^{56}$ & Neonate/M & Choroidal & PD, CHF, ASD & Embolization (TA) & Died \\
\hline Komiyama et $\mathrm{al}^{60}$ & Neonate/M & Choroidal & $\mathrm{CHF}$ & $\begin{array}{l}\text { Femoral TA } \\
\text { Embolization }\end{array}$ & Died \\
\hline Orlov et al ${ }^{48}$ & Neonate/M & Choroidal & $\mathrm{H}$ & Embolization (TA) & Mild DD \\
\hline Heuer et al ${ }^{50}$ & Neonate/M & Choroidal & RVD, PFO, Sz, ischemia, & Embolization & Severe MR \\
\hline Heuer et al ${ }^{50}$ & Neonate/F & Choroidal & HF, Sz, ischemia, & Embolization & Hemiparesis, mild MR \\
\hline Heuer et $\mathrm{al}^{50}$ & $14 \mathrm{mo} / \mathrm{M}$ & Choroidal & Sz, ischemia & Embolization & $\begin{array}{l}\text { Hemiparesis, autistic, } \\
\text { epilepsy in remission }\end{array}$ \\
\hline Heuer et $\mathrm{al}^{50}$ & $45 \mathrm{~d} / \mathrm{M}$ & Choroidal & PFO, hemorrhage & Embolization & $\mathrm{H}$, mild motor delay \\
\hline Demartini et al $^{47}$ & Neonate/M & Choroidal & $\mathrm{HF}, \mathrm{PC}, \mathrm{DD}, \mathrm{V}$ & Embolization (TA and TV) & Improved \\
\hline Fourie et al ${ }^{61}$ & Neonate/M & Choroidal & PC, CHF, cerebral bruit & Embolization (TA and TV) & Improved \\
\hline $\begin{array}{l}\text { Jagadeesan } \\
\text { et al }\end{array}$ & Neonate/M & Mixed type & ASD, PFO & Embolization (TV and TA) & Dysconjugate gaze \\
\hline Levrier et $\mathrm{al}^{13}$ & $11 \mathrm{y} / \mathrm{F}$ & Mixed type & MC, MR, H & Embolization (TV and TA) & Improved \\
\hline
\end{tabular}

Abbreviations: ANP, abducens nerve palsy; ASD, atrial septal defect; CD, cardiomegaly; CHF, congestive heart failure; DFV, dilate scalp and facial veins; DVA, decreased visual acuity; F, female; GKRS, Gamma Knife radiosurgery; H, hydrocephalus; HF, heart failure; HM, hepatomegaly; IHC, increasing head circumference; IVH, intraventricular hemorrhage; LSH, left sided hemiparesis; LVH, left ventricular hypertrophy; M, male; MC, macrocrania; MR, mental retardation; NSC, nasal and sinus congestion; PC, perioral cyanosis; DD, delay development; PD, prenatal diagnosis; PDA, patent ductus arteriosus; PFO, patent foramen ovale; RD, respiratory distress; RVD, right ventricular dilation; RVH, right ventricular hypertrophy; Sz, seizure; TA, transarterial; TV, transvenous; V, vomiting; VAGM, vein of Galen aneurysmal malformation. 
Table 6 Literature review of clinical outcomes after treatment of VGAM in adult

\begin{tabular}{|l|l|l|l|l|l|}
\hline Authors & Age/sex & Type & Clinical features & Treatment & Outcome \\
\hline Gupta et al ${ }^{26}$ & $21 \mathrm{y} / \mathrm{F}$ & Mural & H, SAH, neck stiffness & Embolization (TA) & Normal \\
\hline Levrier et al & $40 \mathrm{y} / \mathrm{M}$ & Mural & Pituitary dysfunction & $\begin{array}{l}\text { Femoral TA } \\
\text { Embolization }\end{array}$ & Normal \\
\hline Ellis et al $^{137}$ & $24 \mathrm{y} / \mathrm{M}$ & Mural & Face pain, dementia & Embolization & Normal \\
\hline Xu et al $^{17}$ & $44 \mathrm{y} / \mathrm{F}$ & Choroidal & Dizziness, vertigo & None & Normal \\
\hline Gupta et al $^{26}$ & $28 \mathrm{y} / \mathrm{M}$ & Choroidal & HA, IVH & Embolization (TV and TA) & Died \\
\hline Porzionato et al & $36 \mathrm{y} / \mathrm{M}$ & Choroidal & IVH, coma & VS & Died \\
\hline Triffo et al & $27 \mathrm{y} / \mathrm{M}$ & Choroidal & RTH, VM & GKRS & DFNT \\
\hline
\end{tabular}

Abbreviations: DFNT, dysmetria on finger-to-nose test; F, female; GKRS, Gamma Knife radiosurgery; H, hydrocephalus; HA, headache; IVH, intraventricular hemorrhage; $\mathrm{M}$, male; RTH, right thalamic hemorrhage; SAH, subarachnoid hemorrhage; TA, transarterial; TV, transvenous; VAGM, vein of Galen aneurysmal malformation; VM, ventriculomegaly; VS, ventricle-peritoneal shunt.

\section{Conclusion}

VGAM is a rare congenital intracranial arteriovenous deformation associated with high mortality. To increase and ameliorate the VGAM diagnosis and therapy, it is crucial to fully understand the pathogenesis, clinical classification, and features of this condition. Imaging plays an important role in the visualization of vascular architecture and also in assisting the treatment with embolization procedures. The evaluation of the time and stages for endovascular treatment based on the score systems will be beneficial to decrease the complication rate, morbidity, and mortality.

\section{Conflict of Interest}

None declared.

\section{Acknowledgment}

This work was supported by the key project of the Tianjin Health and Family Planning Commission Natural Science Foundation (grant number: 2015KR12); the key project of the Tianjin Health Care Professionals (grant number: 16KG166); and the National Natural Science Foundation of China (grant number: 81771589).

\section{References}

1 Stephan S, Rodesch G, Elolf E, Wiemann D, Jorch G. Vein of Galen aneurysmal malformations: an ultrasonographic incidental finding-a case report. Case Rep Pediatr 2012;2012: 824284

2 Kośla K, Majos M, Polguj M, Antosik-Biernacka A, Stefańczyk L, Majos A. Prenatal diagnosis of a vein of Galen aneurysmal malformation with MR imaging - report of two cases. Pol J Radiol 2013;78(04):88-92

3 Dandy WE. Arteriovenous aneurysm of the brain. Arch Surg 1982; 17(02):190-243

4 Boldrey E, Miller ER. Arteriovenous fistula (aneurysm) of the great cerebral vein (of Galen) and the circle of Willis; report on two patients treated by ligation. Arch Neur Psych 1949;62(06): 778-783

5 Jaeger JR, Forbes RP, Dandy WE. Bilateral congenital cerebral arteriovenous communication aneurysm. Trans Am Neurol Assoc 1937;63:173-176
6 Gailloud P, O'Riordan DP, Burger I, et al. Diagnosis and management of vein of Galen aneurysmal malformations. J Perinatol 2005;25(08):542-551

7 Yan J, Wen J, Gopaul R, Zhang CY, Xiao SW. Outcome and complications of endovascular embolization for vein of Galen malformations: a systematic review and meta-analysis. J Neurosurg 2015;123 (04):872-890

8 Raybaud CA, Strother CM. Persisting abnormal embryonic vessels in intracranial arteriovenous malformations. Acta Radiol Suppl 1986;369(369):136-138

9 Chauhan U, Tullu M, Muranjan M, Lahiri K. Thalamic haemorrhage: a rare presentation of vein of Galen aneurysmal malformation in infancy. N Z Med J 2003;116(1186):U687

10 Cai CQ Zhang QJ, Yang WD, Wang CX, Shen CH. Neuroimages of persistent falcine sinus in children. World J Pediatr 2009;5(01): 63-64

11 Iizuka Y, Kakihara T, Suzuki M, Komura S, Azusawa H. Endovascular remodeling technique for vein of Galen aneurysmal malformations-angiographic confirmation of a connection between the median prosencephalic vein and the deep venous system. J Neurosurg Pediatr 2008;1(01):75-78

12 Gailloud P, O'riordan DP, Burger I, Lehmann CU. Confirmation of communication between deep venous drainage and the vein of Galen after treatment of a vein of Galen aneurysmal malformation in an infant presenting with severe pulmonary hypertension. Am J Neuroradiol 2006;27(02):317-320

13 Levrier O, Gailloud PH, Souei M, Manera L, Brunel H, Raybaud C. Normal galenic drainage of the deep cerebral venous system in two cases of vein of Galen aneurysmal malformation. Childs Nerv Syst 2004;20(02):91-97, discussion 98-99

14 Revencu N, Boon LM, Mulliken JB, et al. Parkes Weber syndrome, vein of Galen aneurysmal malformation, and other fast-flow vascular anomalies are caused by RASA1 mutations. Hum Mutat 2008;29(07):959-965

15 Chida A, Shintani M, Wakamatsu H, et al. ACVRL1 gene variant in a patient with vein of Galen aneurysmal malformation. J Pediatr Genet 2013;2(04):181-189

16 Tsutsumi Y, Kosaki R, Itoh Y, et al. Vein of Galen aneurysmal malformation associated with an endoglin gene mutation. Pediatrics 2011;128(05):e1307-e1310

17 Xu DS, Usman AA, Hurley MC, Eddleman CS, Bendok BR. Adult presentation of a familial-associated vein of Galen aneurysmal malformation: case report. Neurosurgery 2010;67(06):E1845-E1851, discussion 1851

18 Litvak J, Yahr MD, Ransohoff J. Aneurysms of the great vein of Galen and midline cerebral arteriovenous anomalies. J Neurosurg 1960;17:945-954 
19 Lasjaunias P, Ter Brugge K, Lopez Ibor L, et al. The role of dural anomalies in vein of Galen aneurysms: report of six cases and review of the literature. Am J Neuroradiol 1987;8(02):185-192

20 Triffo WJ, Bourland JD, Couture DE, McMullen KP, Tatter SB, Morris PP. Definitive treatment of vein of Galen aneurysmal malformation with stereotactic radiosurgery. J Neurosurg 2014;120(01): 120-125

21 Pearl M, Gomez J, Gregg L, Gailloud P. Endovascular management of vein of Galen aneurysmal malformations. Influence of the normal venous drainage on the choice of a treatment strategy. Childs Nerv Syst 2010;26(10):1367-1379

22 Lasjaunias PL, Chng SM, Sachet M, Alvarez H, Rodesch G, GarciaMonaco R. The management of vein of Galen aneurysmal malformations. Neurosurgery 2006;59(05, Suppl 3):S184-S194, discussion $\mathrm{S} 3-\mathrm{S} 13$

23 Puvabanditsin S, Mehta R, Palomares K, et al. Vein of Galen malformation in a neonate: a case report and review of endovascular management. World J Clin Pediatr 2017;6(01):103-109

24 Yasargil MG. Microneurosurgery IIIB. New York: Thieme Medical Publishers; 1988:323-357

25 Mortazavi MM, Griessenauer CJ, Foreman P, et al. Vein of Galen aneurysmal malformations: critical analysis of the literature with proposal of a new classification system. J Neurosurg Pediatr 2013; 12(03):293-306

26 Gupta AK, Varma DR. Vein of Galen malformations: review. reviewNeurol India 2004;52(01):43-53

27 Tang F, Zhang L, Huang X, Li XW, Zhang Y, Zhai XW. Effects of intravascular embolization operation on adult VGAD. Eur Rev Med Pharmacol Sci 2016;20(09):1829-1833

28 Iizuka Y, Kakihara T, Yoshimura N, Kimizuka T, Sumi Y, Kaneko K. Anatomical subcategorization for pediatric vein of Galen aneurysmal dilatation. A report of three cases. Neuroradiol J 2007;20 (05):551-561

29 Gold A, Ransohoff J, Carter S. Vein of Galen malformation. Acta Neurol Scand Suppl 1964;40(Suppl 11):1-31

30 Filippi L, Pezzati M, Poggi C, Pasquini E. Vein of Galen aneurysmal malformation and galactosemia in a neonate: a previously unreported association. Paediatr Anaesth 2007;17(12):1221-1223

31 de Souza A, Fernandes YS, Bhatkar SR, Bhonsle SK. Chronic asymmetric tremor and levodopa-responsive parkinsonism due to a vein of Galen aneurysmal malformation. Parkinsonism Relat Disord 2017;43:122-123

32 Agarwal A, Firdouse M, De Almeida CL, Mondal T. Distinctive neck swelling in a patient with a vein of Galen arteriovenous malformation. J Ultrasound 2014;18(02):197-200

33 Saliou G, Dirks P, Slater LA, Krings T. Is jugular bulb stenosis in vein of Galen aneurysmal malformation associated with bony remodeling of the jugular foramina? J Neurosurg Pediatr 2016;18(01):92-96

34 Frankenburg WK, Dodds J, Archer P, Shapiro H, Bresnick B. The Denver II: a major revision and restandardization of the Denver Developmental Screening Test. Pediatrics 1992;89(01):91-97

35 Bohiltea RE, Turcan N, Mihalea C, et al. Ultrasound prenatal diagnosis and emergency interventional radiologic therapy of Galen aneurysmal malformation in a newborn. Maedica (Buchar) 2016;11(04):334-340

36 Geibprasert S, Krings T, Armstrong D, Terbrugge KG, Raybaud CA. Predicting factors for the follow-up outcome and management decisions in vein of Galen aneurysmal malformations. Childs Nerv Syst 2010;26(01):35-46

37 Deloison B, Chalouhi GE, Sonigo P, et al. Hidden mortality of prenatally diagnosed vein of Galen aneurysmal malformation: retrospective study and review of the literature. Ultrasound Obstet Gynecol 2012;40(06):652-658

38 Cai C, Zhang Q, Shen C. Vein of Galen malformations-report of 2 cases and literature review. Front Med China 2008;2(03):317-322

39 Schnell S, Wu C, Ansari SA. Four-dimensional MRI flow examinations in cerebral and extracerebral vessels - ready for clinical routine? Curr Opin Neurol 2016;29(04):419-428
$40 \mathrm{Wu} \mathrm{C}$, Schoeneman SE, Kuhn R, et al. Complex alterations of intracranial 4D hemodynamics in vein of Galen aneurysmal malformations during staged endovascular embolization. Operative Neurosurgery 2016;12(03):1

41 Irfan M, Lohman B, McKinney AM. Confirmation of T1-bright vein of Galen aneurysm spontaneous thrombosis by subtraction magnetic resonance venography: a case report. Acta Radiol 2009;50 (07):812-815

42 Joo W, Mercier P, Kheradmand S, et al. Vein of Galen malformation treated with the Micro Vascular Plug system: case report. J Neurosurg Pediatr 2017;19(06):729-733

43 Mahmoodi R, Habibi Z, Heidari V, Nejat F. Spontaneous regression and complete disappearance of the vein of Galen aneurysmal malformation. Childs Nerv Syst 2016;32(04):593-598

44 Pearl M, Gregg L, Gandhi D. Cerebral venous development in relation to developmental venous anomalies and vein of Galen aneurysmal malformations. Semin Ultrasound CT MR 2011;32 (03):252-263

45 Davis PB. Thrombosis of the internal cerebral veins of Galen; report of two cases involving adults. J Am Osteopath Assoc 1950; 50(01):21-22

46 Berenstein A, Fifi JT, Niimi Y, et al. Vein of Galen malformations in neonates: new management paradigms for improving outcomes. Neurosurgery 2012;70(05):1207-1213, discussion 1213-1214

47 Demartini Z Jr, Dos Santos ML, Koppe GL, Cardoso-Demartini AA. Sinus thrombosis after endovascular treatment of vein of Galen aneurysmal malformation. Pediatr Neurosurg 2017;52 (02):136-139

48 Orlov K, Gorbatykh A, Berestov V, et al. Superselective transvenous embolization with Onyx and n-BCA for vein of Galen aneurysmal malformations with restricted transarterial access: safety, efficacy, and technical aspects. Childs Nerv Syst 2017;33 (11):2003-2010

49 Meila D, Hannak R, Feldkamp A, et al. Vein of Galen aneurysmal malformation: combined transvenous and transarterial method using a "kissing microcatheter technique". Neuroradiology 2012; 54(01):51-59

50 Heuer GG, Gabel B, Beslow LA, et al. Diagnosis and treatment of vein of Galen aneurysmal malformations. Childs Nerv Syst 2010; 26(07):879-887

51 Sharma J, Toubas P, Sklar T, Pole-Spellman J. Spontaneous resolution of marked dilatation of cerebral duro-venous system in newborn presenting with fetal hydrops. Indian J Pediatr 2010; 77(03):313-315

52 Xu H, Zheng J, Chen G, Chen J. Hemispheric developmental venous anomaly draining into a vein of Galen varix: a case report and literature review. Chin J Neurosurg 2017;3(02):1

53 Agarwal H, Sebastian LJ, Gaikwad SB, Garg A, Mishra NK. Vein of Galen aneurysmal malformation-clinical and angiographic spectrum with management perspective: an institutional experience. J Neurointerv Surg 2017;9(02):159-164

54 Yan J, Gopaul R, Wen J, Li XS, Tang JF. The natural progression of VGAMs and the need for urgent medical attention: a systematic review and meta-analysis. J Neurointerv Surg 2017;9(06): 564-570

55 Pop R, Manisor M, Wolff V, Kehrli P, Marescaux C, Beaujeux R. Flow control using Scepter ${ }^{\mathrm{TM}}$ balloons for Onyx embolization of a vein of Galen aneurysmal malformation. Childs Nerv Syst 2015;31 (01):135-140

56 Jones BV, Ball WS, Tomsick TA, Millard J, Crone KR. Vein of Galen aneurysmal malformation: diagnosis and treatment of 13 children with extended clinical follow-up. Am J Neuroradiol 2002;23 (10):1717-1724

57 Ellis JA, Orr L, Ii PC, Anderson RC, Feldstein NA, Meyers PM. Cognitive and functional status after vein of Galen aneurysmal malformation endovascular occlusion. World J Radiol 2012;4(03): 83-89 
58 Cai MJ, Ma LT, Yang M, Pan L. Vein of Galen aneurysmal malformation: strategy transarterial embolization using coils alone. Neurol India 2012;60(05):559-560

59 Kong JC, Cheng KM, Cheung YL, Chan CM. Transarterial embolisation with Guglielmi detachable coils in an infant with a vein of Galen aneurysmal malformation. Hong Kong Med J 2012;18(05): 435-438

60 Komiyama M, Honnda Y, Matsusaka Y, Morikawa T, Kitano S, Sakamoto H. Cerebral diagnostic and therapeutic angiography for neonatal arteriovenous fistulas. Interv Neuroradiol 2004;10 (Suppl 1):39-42
61 Fourie PA, Potze FP, Hay N, Du Toit E, Lippert MM, Mennen J. Transcranial placement of an amplatzer device to control intractable cardiac failure in an infant with a vein of Galen anomaly. A case report. Interv Neuroradiol 2010;16(02):191-197

62 Jagadeesan BD, Zacharatos H, Nascene DR, Grande AW, Guillaume DJ, Tummala RP. Endovascular management of a vein of Galen aneurysmal malformation in an infant with challenging femoral arterial access. J Neurosurg Pediatr 2016;18(02):231-234

63 Porzionato A, Macchi V, Parenti A, De Caro R. Vein of Galen aneurysm: anatomical study of an adult autopsy case. Clin Anat 2004;17(06):458-462 